\title{
Single nucleotide polymorphisms in the growth hormone and insulin-like growth factor-1 genes are associated with milk production, body condition score and fertility traits in dairy cows
}

\author{
M.P. Mullen ${ }^{1 *}$, C.O. Lynch ${ }^{1 *}$, S.M. Waters ${ }^{2}$, D.J. Howard ${ }^{1}$, P. O’Boyle ${ }^{1}$, \\ D.A. Kenny ${ }^{2}$, F. Buckley ${ }^{3}$, B. Horan ${ }^{3}$ and M.G. Diskin ${ }^{1}$ \\ ${ }^{1}$ Animal and Bioscience Research Department, \\ Animal and Grassland Research and Innovation Centre, Teagasc, \\ Athenry, Co. Galway, ${ }^{2}$ Grange, Dunsany, Co. Meath, ${ }^{3}$ Moorepark, \\ Fermoy, Co. Cork, Ireland \\ *These authors contributed equally to this study. \\ Corresponding author: M.P. Mullen \\ E-mail: michael.mullen@teagasc.ie
}

Genet. Mol. Res. 10 (3): 1819-1830 (2011)

Received November 23, 2010

Accepted February 17, 2011

Published August 26, 2011

DOI http://dx.doi.org/10.4238/vol10-3gmr1173

\begin{abstract}
The somatotrophic axis (GH-IGF) is a key regulator of animal growth and development, affecting performance traits that include milk production, growth rate, body composition, and fertility. The aim of this study was to quantify the association of previously identified SNPs in bovine growth hormone $(\mathrm{GHI})$ and insulinlike growth factor $1(I G F-1)$ genes with direct performance trait measurements of lactation and fertility in Holstein-Friesian lactating dairy cows. Sixteen SNPs in both $I G F-1$ and $G H 1$ were genotyped across 610 cows and association analyses were carried out with traits of economic importance including calving interval, pregnancy rate
\end{abstract}


to first service and 305-day milk production, using animal linear mixed models accounting for additive genetic effects. Two $I G F-1$ SNPs, IGF1i1 and IGF1i2, were significantly associated with body condition score at calving, while a single $I G F-1$ SNP, IGF1i3, was significantly associated with milk production, including milk yield (means \pm SEM; $751.3 \pm 262.0 \mathrm{~kg}$ ), fat yield $(21.3 \pm 10.2 \mathrm{~kg}$ ) and protein yield $(16.5 \pm 8.0 \mathrm{~kg})$ per lactation. Only one GH1 SNP, GH33, was significantly associated with milk protein yield in the second lactation (allele substitution effect of $9.8 \pm 5.0 \mathrm{~kg}$ ). Several GH1 SNPs were significantly associated with fertility, including GH32, GH35 and GH38 with calving to third parity $(22.4 \pm 11.3$ days) ( $G H 32$ and $G H 38$ only), pregnancy rate to first service $(0.1 \%)$ and overall pregnancy rate $(0.05 \%)$. The results of this study demonstrate the effects of variants of the somatotrophic axis on milk production and fertility traits in commercial dairy cattle.

Key words: Single nucleotide polymorphism; Fertility; IGF-1; Growth hormone; Dairy cattle

\section{INTRODUCTION}

Growth hormone (GH) and circulating insulin-like growth factor-1 (IGF-1) are major regulators of postnatal growth and metabolism and thus play critical roles in the control of lactation, mammary gland development, growth processes, and fertility in cattle (Jiang and Lucy, 2001; Renaville et al., 2002; Lucy, 2008). Anterior pituitary-derived GH stimulates the release of circulating IGF-1 from the liver and is critical to the control of nutrient utilization and partitioning (Chagas et al., 2007). Furthermore, in early lactation the somatotrophic axis is uncoupled in high-producing dairy cows so that the liver fails to respond to GH and produces less IGF-1 (Jiang and Lucy, 2001; Renaville et al., 2002; Lucy, 2008). This uncoupling has been implicated in the process of nutrient partitioning, enabling high milk production (Lucy, 2008). The action of GH is mediated through controlling the expression of many genes, including $I G F-1$. Hayhurst et al. (2009) reported a significant relationship between circulating concentrations of GH and calving interval, thereby concluding that GH may potentially be useful as a juvenile selection criterion for fertility. Furthermore, a positive association between systemic concentrations of IGF-1 in the early post-partum period and subsequent cow fertility has been reported (Patton et al., 2007). Such findings suggest that at least some variation of systemic GH and IGF-1 levels is potentially due to mutations within their encoding genes or proximal regulatory regions. Growth hormone $(G H 1)$ and insulin-like growth factor $1(I G F-1)$ genes are therefore promising candidates for dissecting the genetics affecting performance, which may also identify genetic markers for improving fertility and milk production in cattle. Our group has identified significant associations between single nucleotide polymorphisms (SNPs) in $I G F-1$ and $G H 1$ and production traits in Holstein-Friesian (HF) cattle (Mullen et al., 2010, 2011), where the dependent variable was genetic merit of the bull, based on progeny performance. However, there is no published information on the direct association or effects of SNPs in GHI and $I G F-1$ with 
HF cows exhibiting the performance traits. Thus, the aim of this study was to determine if associations exist between SNPs in $G H I$ and $I G F-I$ and fertility and milk production traits in lactating dairy cows.

\section{MATERIAL AND METHODS}

\section{Animal material and phenotype recording}

Blood samples were collected via the coccygeal vein from 610 Holstein-Friesian dairy cows from 10 herds ( 6 commercial and 4 research herds) across Ireland in 2008. All blood collection was conducted under license in accordance with the European Community Directive, 86-609-EC.

Experimental treatments within the four research herds were treated as separate herds and contemporary group was subsequently defined as herd-year-month of calving. In all cases, cows with calving interval $<300$ or $>500$ days were discarded. Furthermore, cows were excluded if insufficient information was available for a given trait. The number of cows, which were included for analysis of each trait, is given in the text. First, second and third 305-day milk, fat and protein yields were available on 392, 237 and 152 cows, respectively. Lactation 305-day yields were estimated using standard lactation curve methodology outlined by Olori and Galesloot (1999). Calving interval from first to second, second to third and third to fourth lactation were available on 369, 242 and 148 cows, respectively. Pregnancy rate was assessed by ultrasound scanning in 2006 on 362 cows. This was conducted initially at 30 to 50 days and subsequently at 100 days post-insemination, and service records and subsequent calving records were collected. This information was used to derive pregnancy rate to first service, overall pregnancy rate and calving to first service interval. Of these 362 cows, 241 had records of body condition score at calving. Each cow was scored within the first week of calving in each case using a 5-point scale (Wildman et al., 1982; Edmonson et al., 1989).

\section{DNA extraction and genotyping}

DNA was extracted from whole blood using a proteinase K/salting out/ethanol precipitation extraction method (adapted from Montgomery and Sise, 1990). Following extraction, the quality and quantity of DNA extracted were assessed using a Nanodrop ${ }^{\circledR}$ spectrophotometer (ThermoScientific, USA) and agarose gel electrophoresis.

A total of 16 SNPs, 10 SNPs spanning the intronic and 3 ' regions of $I G F-1$ and 6 SNPs from the 5 ' region of $G H 1$ were genotyped across the 610 cows (Table 1). SNP genotyping was carried out commercially using the Sequenom MassArray ${ }^{\circledR}$ iPLEX Gold assay (Sequenom, San Diego, CA, USA).

\section{Transcription factor binding site analysis}

Bioinformatic analysis was carried out on SNP GH33 located in the promoter region of $\mathrm{GHI}$ to examine the effects of allele substitution on transcription factor binding sites predicted by the MatInspector software package (Cartharius et al., 2005). 


\section{Statistical procedures}

The association between each of the SNPs and performance was determined using animal linear mixed models in ASREML (Gilmour et al., 2009) accounting for the additive genetic relationship among animals. Analyses were undertaken within parity for milk production and calving interval. Heritability estimates for yield and calving interval were fixed at 0.35 and 0.03 , respectively. Fixed effects included in the model were Holstein breed fraction and contemporary group. Only one record on calving to first service interval, pregnancy rate to first service, and overall pregnancy rate was available for all animals, and therefore, the association between each SNP and these fertility traits was determined across all parities in a model that included parity, contemporary group and Holstein breed fraction as fixed effects.

\section{RESULTS}

One of the $I G F-1$ SNP frequencies in this study deviated from Hardy-Weinberg equilibrium (HWE); IGF1i2 due to homozygote deficiencies. Eight of the 10 segregating IGF-1 SNPs were segregating with minor allele frequencies (MAF) $\leq 5 \%$ (Table 1 ).

The $\mathrm{G}$ allele of IGF1i3 was associated $(\mathrm{P}<0.05)$ with increased milk yield in lactation one (means \pm SEM; $398 \pm 173.0 \mathrm{~kg})$ and two $(751.3 \pm 262.0 \mathrm{~kg})$, increased fat yield in lactation one $(18.8 \pm 6.8 \mathrm{~kg})$ and two $(21.3 \pm 10.2 \mathrm{~kg})$, and increased protein yield in lactation two $(16.5 \pm 8.0 \mathrm{~kg})$. IGF1i1 and IGF1i2 were each associated $(\mathrm{P}<0.05, \mathrm{P}<0.001$, respectively $)$ with body condition score at calving (Table 2).

Five of the six GH1 SNPs were in HWE with MAF between 0.09 to 0.45 . The remaining GH1 SNP (GH36) was fixed in the population (Table 1).

Only one SNP, GH33, was associated with milk production, where the T allele was associated $(\mathrm{P}<0.05)$ with increased milk yield in lactation two $(9.8 \pm 5.0 \mathrm{~kg})$.

No SNP was associated $(\mathrm{P}>0.05)$ with calving to first service. GH32 and GH38 were associated $(\mathrm{P}<0.05)$ with calving to third parity and GH32, GH35 and GH38 were associated $(\mathrm{P}<0.05)$ with pregnancy to first service and overall pregnancy rate (Table 2). Transcription factor site analysis showed that SNP GH33 modulated a single predicted transcription factor binding sites (pTFBS), for the PAX-2 family of transcription factors (Table 3).

\section{DISCUSSION}

Apart from our own studies in HF sires (Mullen et al., 2010, 2011) there is little published information on $I G F-1$ and $G H 1$ polymorphisms and their association with traits of economic importance in HF cattle. In particular, there is a dearth of information regarding direct associations between $I G F-1$ and $G H 1$ polymorphisms and milk production and fertility traits in dairy cows. The present study describes the identification of previously reported SNPs in $I G F-1$ and $G H 1$ in commercial dairy cows and novel associations with milk yield and composition, body condition score and fertility (Table 2).

\section{IGF-1 SNPs}

Eight of the 10 segregating IGF-1 SNPs had an MAF of $\leq 5 \%$, other studies from this 


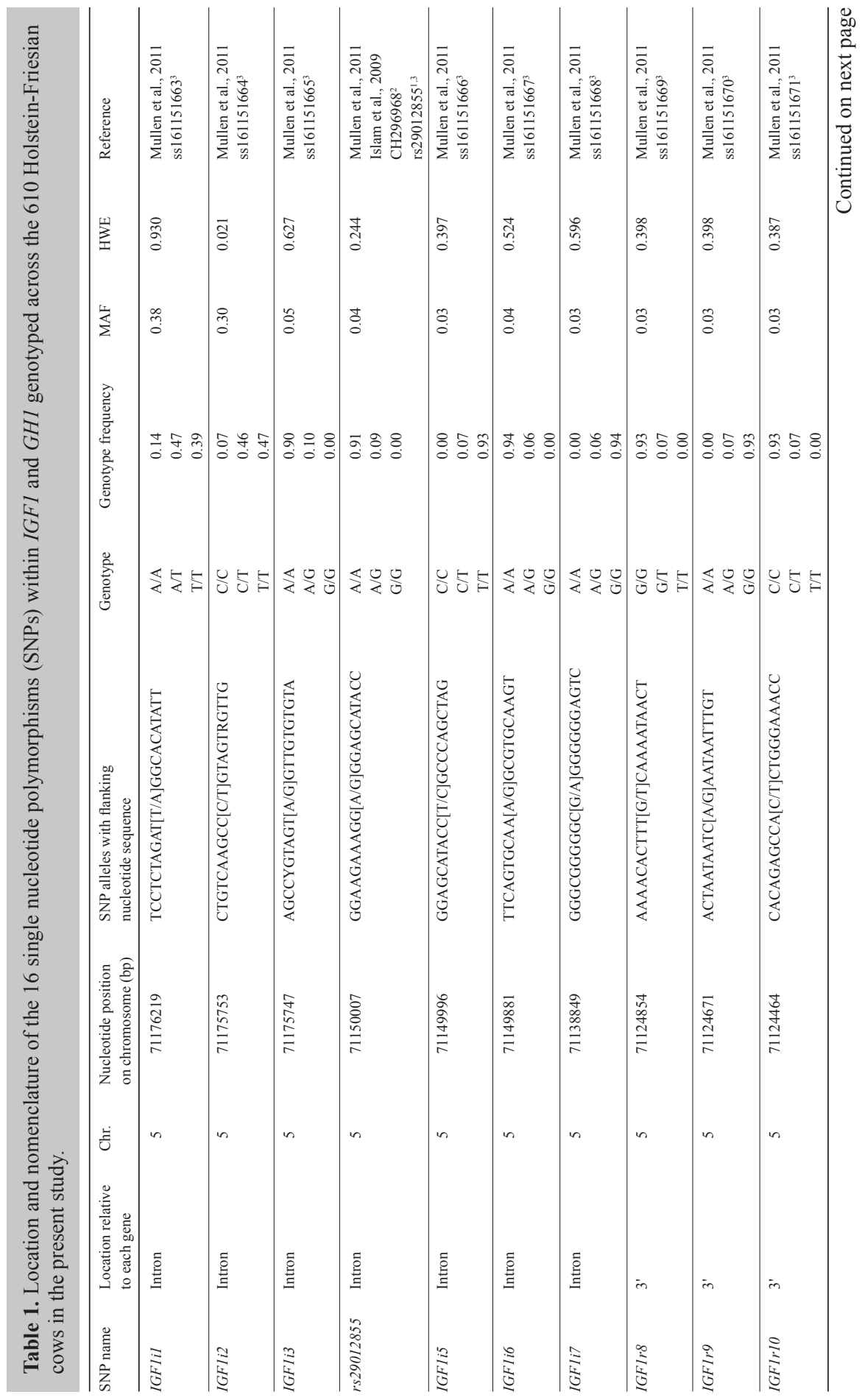


M.P. Mullen et al.

1824

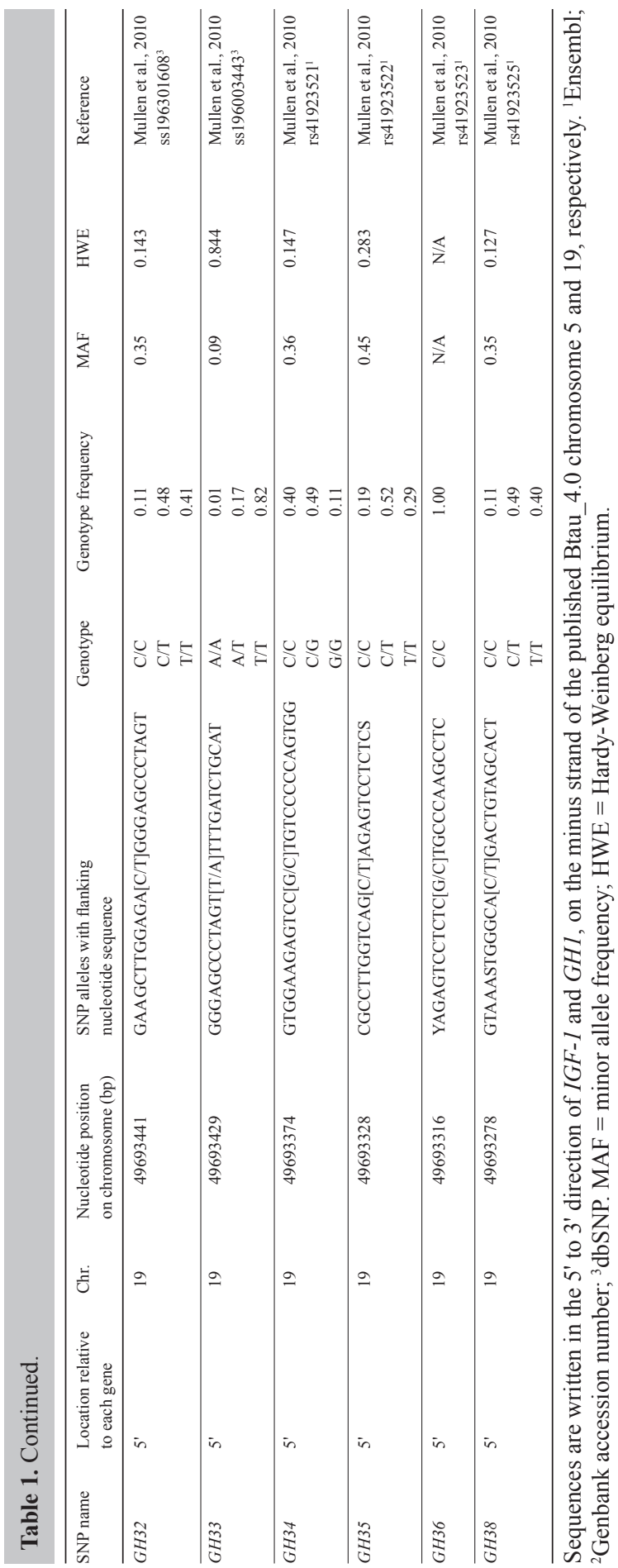

Genetics and Molecular Research 10 (3): 1819-1830 (2011) 
SNPs in bovine $I G F 1$ and $G H 1$

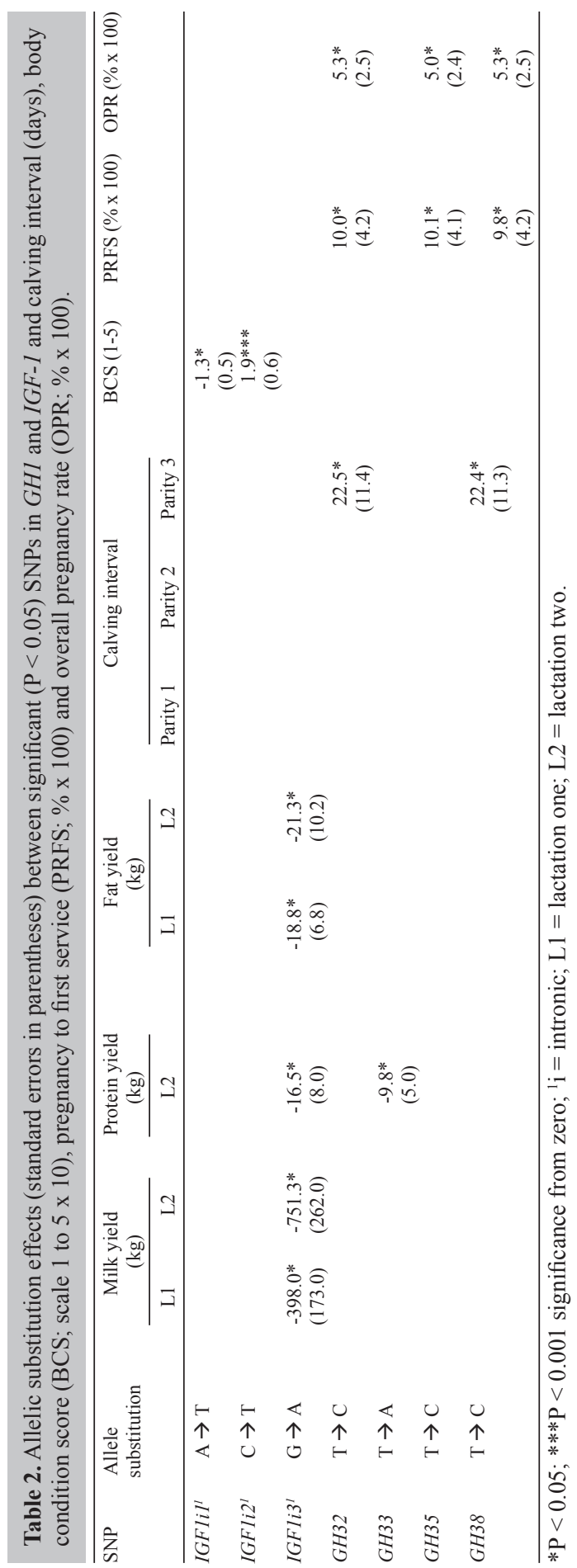


Table 3. Effects of bovine GH1 5'UTR single nucleotide polymorphisms (SNPs) on predicted transcription factor binding sites ${ }^{1}$.

\begin{tabular}{lllcll}
\hline SNP ID & Allele & Core similarity & Matrix similarity & Site sequence & Transcription factor binding sites \\
\hline GH35 & C & 1.0 & 0.998 & aggactctGCTGaccaaggcg & MAF and AP1-related factors \\
& $\mathrm{C}$ & 1.0 & 0.866 & cgccttGGTCagcagagtctctcs & RXR heterodimer binding sites \\
GH38 & $\mathrm{C}$ & 0.978 & 0.721 & aaactgctttggagctgagaagtgctacaGTCGtgccc & General transcription factor IID (GTF2D) \\
& $\mathrm{T}$ & 1.0 & 0.952 & gagaagtgctacagtCATGccca & p53 tumor suppressor \\
GH33 & $\mathrm{T}$ & 1.0 & 0.785 & tagaggatgcagatcaaAAACta & PAX-2 binding sites \\
\hline
\end{tabular}

${ }^{1}$ The "core sequence" of a matrix is defined as the (usually 4) consecutive highest conserved positions of the matrix (marked in capital letters). A perfect match between the consensus bovine sequence and the matrix gets a score of 1.00 (each sequence position corresponds to the highest conserved nucleotide at that position in the matrix), a "good" match with the matrix usually has a similarity of $>0.80$. MAF $=$ musculoaponeurotic fibrosarcoma oncogene; AP1 = activator protein 1; RXR = retinol X receptor. Adapted from Mullen et al., 2010.

group have shown similar MAF for these 10 SNPs in a separate population of $848 \mathrm{HF}$ sires (Mullen et al., 2010, 2011) validating their segregation, yet low MAF, within this breed.

Previous studies reporting association analysis of variants of $I G F-1$ and milk production and growth traits in cattle include $I G F-1$ SNPs [AF017143 (Ge et al., 2001; Siadkowska et al., 2006; Islam et al., 2009) and $r s 29012855$ (Islam, 2009)]. In the present study, IGF1i3 was associated with milk yield, milk fat yield and milk protein yield. In addition, IGF1i3 was also associated with milk composition but not with milk yield in the previously mentioned cohort of sires based on daughter performance (Mullen et al., 2011). To our knowledge, this is the first reporting of a polymorphism in $I G F-1$ associated directly with milk yield in cattle. Consistent with this, IGF-1 plays an important role in mammary gland growth and function by regulating several cellular processes (Akers, 2006), including the stimulation of protein synthesis in the epithelial cells of the mammary gland (Burgos and Cant, 2010). Furthermore, plasma IGF-1 correlates with milk production throughout lactation and particularly around mating start date and late lactation; circulating IGF-1 has been shown to be positively correlated with milk yield (Rose et al., 2005), and other studies have shown plasma IGF-1 to be positively correlated with milk fat concentrations (Moyes, 2004).

The results of the present study suggest that variants of $I G F-1$ segregating at low frequency in HF cattle are associated with milk production. Low frequency and rare alleles have been speculated to contribute to the missing heritability described from large-scale genomewide association studies of complex traits (Manolio et al., 2009). This reemphasizes the relevance of the candidate gene re-sequencing approach to help uncover rare variants, especially in genes with established physiological effects such as $I G F-1$.

It is well established that gene transcription is extensively and co-ordinately regulated. Although introns are known to carry regulatory sequences, they may not have a direct involvement in the regulation of transcription of highly expressed genes; however, systematic differences in motif distributions do suggest that introns play a role in the rate of their transcription (Zhang et al., 2008). Of the seven SNPs located within introns of $I G F-1$, two SNPs (IGFIi1 and IGF1i2) were associated with body condition score, supporting a role of $I G F-1$ in nutrient partitioning in cattle. Indeed, studies have described a relationship between systemic IGF-1 and carcass fat; Davis and Simmen (2000) reported that Angus bulls with lower plasma IGF-1 concentrations had higher marbling scores and 
back fat thickness. Similarly, circulating IGF-1 was found to be negatively correlated with carcass fat percentage, fat accretion rate and fat thickness in Simmental crossbred bulls (Anderson et al., 1988). Furthermore, studies in transgenic mice have shown that the differentiation stage of precursor cells into mature fat cells is accompanied by enhanced expression of IGF-1 (Rajkumar et al., 1999) indicating a role of IGF-1 in fat cell developmental processes.

\section{GH1 SNPs}

Studies involving GH1 SNPs and production traits in cattle have mainly centered on two SNPs, 2141 (Lucy et al., 1993; Yao et al., 1996; Ge et al., 2003) and 2291 (Yao et al., 1996; Lagziel and Soller, 1999), located in exon 5. The importance and complexity of the regulatory elements within the 5'UTR and their effects on gene expression are well accepted (Cheung and Spielman, 2009). Studies have shown the relevance of polymorphisms of the 5 'UTR of the bovine growth hormone receptor gene (GHR), with several significant associations with milk production and body size traits in HF cattle (Waters et al., 2011). In this study, we examined the 5' region of $G H 1$, with all 6 SNPs located upstream of the first exon of GH1, according to assembly Btau 4.0 (http://www.ensembl.org; accessed April 14, 2010).

Only one SNP, GH33, was associated with milk production while several GH1 SNPs were associated with fertility in the present study, as measured by calving interval, pregnancy rate to first service and overall pregnancy rate. Although no SNP was associated with calving to first service interval, $G H 32$ and $G H 38$ were associated with calving to third parity, and GH32, GH35 and GH38 with pregnancy to first service and overall pregnancy rate. To our knowledge, this is the first reporting of SNPs in the 5' region of GH1, associated with directly measured fertility traits in dairy cattle. Associations with indirect fertility indicators, such as survival, have been observed by our group for GH35 (Mullen et al., 2010). Furthermore, associations between GH32, GH35 and GH38 and other production traits, including somatic cell count, survival (as mentioned above), carcass conformation, body depth, angularity, and stature, have previously been observed in HF cattle (Mullen et al., 2010). Although these traits were not examined in this study, coupled with the present evidence, these results support the argument that polymorphisms within or in linkage disequilibrium (LD) with the 5 ' region of GH1 have direct effects on production traits in cattle.

Potential mechanisms for the observed effects of GH32, GH35 and GH38 polymorphisms have been previously examined in silico (Mullen et al., 2010), whereas novel mechanisms are discussed herein for the effects observed for GH33 (Table 3). GH35 and GH38 both introduce differential pTFBS and may mediate their effects through modulation of the binding efficiency of $\mathrm{GH} 1$ transcription factors. The C allele of GH35 introduced pTFBS for musculoaponeurotic fibrosarcoma oncogene/activator protein 1 and retinoid $\mathrm{X}$ receptor (RXR) heterodimers. Activator protein- 1 mediates many mammalian cell physiological processes and has been shown to be involved in transcriptional regulation of the chicken IGF-1 gene (Umayahara et al., 1994), whereas RXR heterodimers modify chromatin structure within the promoter region and recruit transcriptional machinery to initiate transcription (Hebbar and Archer, 2003). The SNP GH38, altered 2 pTFBS; first, for general transcription factor IID (GTF2D), known to be involved in transcriptional regulation of hepatic genes in mice (Tatarakis et al., 2008), and second, for p53 tumor suppressor, which in part functions as a 
transcriptional activator of many target genes, including $I G F B P 3$, which modulates the mitogenic effects of $I G F-1$ (Buckbinder et al., 1995). The SNP GH33 modulated a single pTFBS, for the PAX-2 family of transcription factors. The PAX family of transcription factors is an ancient and remarkably conserved gene family, identified in many animal species (Vorobyov and Horst, 2006) and have been shown to play a key role in regulating a variety of genes involving growth and development in a tissue specific manner (Buckingham and Relaix, 2007). PAX2, in particular, interacts with Pax transactivation domain-interacting protein (PTIP), which contains a carboxyl-terminal domain (BRCT) associated with active chromatin (Lechner et al., 2000), thereby potentially controlling access to the promoter region of $G H 1$.

Although it is not predicted to affect TFBS directly, GH32 may mediate its effects through LD with proximal causative variant(s), which could include $G H 35$ or $G H 38$ or both. While biological rationales for the possible mechanisms of the associations with $G H 35$, and GH38 and production traits have been proposed, the observed effects may also be due to other mutations in LD with these SNPs.

\section{CONCLUSIONS}

The present study has described novel associations of previously identified SNPs in both $I G F-1$ and $G H 1$ with economically important traits in dairy cows, reaffirming the importance and established role of the somatotrophic axis in animal metabolism, fertility and milk production. Whether the associations observed in this study are due to functional effects of these SNPs is unknown and may be due to LD with caustive polymorphisms as yet undetected in bovine $I G F-1$ or $G H 1$ or nearby regions of the genome. Despite the importance of the somatotrophic axis, there is a dearth of information on causative variants within this axis, and therefore, future study could include re-sequencing of the complete bovine $I G F-1$ and $G H 1$ genes, alternate transcripts and transcriptional regulators in animals divergent for traits of economical importance. This approach could identify potential causative polymorphisms, which if augmented with functional genomic studies and validated in independent populations of cattle would yield greater insight into the influence of variants of $I G F-1$ and GH1 on performance.

\section{ACKNOWLEDGMENTS}

Research supported by Science Foundation Ireland (\#07/SRC/B1156).

\section{REFERENCES}

Akers RM (2006). Major advances associated with hormone and growth factor regulation of mammary growth and lactation in dairy cows. J. Dairy Sci. 89: 1222-1234.

Anderson PT, Bergen WG, Merkel RA, Enright WJ, et al. (1988). The relationship between composition of gain and circulating hormones in growing beef bulls fed three dietary crude protein levels. J. Anim. Sci. 66: 3059-3067.

Buckbinder L, Talbott R, Velasco-Miguel S, Takenaka I, et al. (1995). Induction of the growth inhibitor IGF-binding protein 3 by p53. Nature 377: 646-649.

Buckingham M and Relaix F (2007). The role of Pax genes in the development of tissues and organs: Pax3 and Pax7 regulate muscle progenitor cell functions. Annu. Rev. Cell Dev. Biol. 23: 645-673.

Burgos SA and Cant JP (2010). IGF-1 stimulates protein synthesis by enhanced signaling through mTORC1 in bovine mammary epithelial cells. Domest. Anim. Endocrinol. 38: 211-221. 
Cartharius K, Frech K, Grote K, Klocke B, et al. (2005). MatInspector and beyond: promoter analysis based on transcription factor binding sites. Bioinformatics 21: 2933-2942.

Chagas LM, Bass JJ, Blache D, Burke CR, et al. (2007). Invited review: new perspectives on the roles of nutrition and metabolic priorities in the subfertility of high-producing dairy cows. J. Dairy Sci. 90: 4022-4032.

Cheung VG and Spielman RS (2009). Genetics of human gene expression: mapping DNA variants that influence gene expression. Nat. Rev. Genet. 10: 595-604.

Davis ME and Simmen RC (2000). Genetic parameter estimates for serum insulin-like growth factor-I concentration and carcass traits in Angus beef cattle. J. Anim. Sci. 78: 2305-2313.

Edmonson AJ, Lean IJ, Weaver LD, Farver T, et al. (1989). A body condition scoring chart for holstein dairy cows. Dairy Sci. 72: 68-78.

Ge W, Davis ME, Hines HC, Irvin KM, et al. (2001). Association of a genetic marker with blood serum insulin-like growth factor-I concentration and growth traits in Angus cattle. J. Anim. Sci. 79: 1757-1762.

Ge W, Davis ME, Hines HC, Irvin KM, et al. (2003). Association of single nucleotide polymorphisms in the growth hormone and growth hormone receptor genes with blood serum insulin-like growth factor I concentration and growth traits in Angus cattle. J. Anim. Sci. 81: 641-648.

Gilmour AR, Cullis BR, Welham SJ and Thompson R (2009). ASREML Reference Manual: New South Wales Agriculture, Orange Agricultural Institute, Orange.

Hayhurst C, Flint AP, Lovendahl P, Woolliams JA, et al. (2009). Genetic variation of metabolite and hormone concentration in UK Holstein-Friesian calves and the genetic relationship with economically important traits. J. Dairy Sci. 92: 4001-4007.

Hebbar PB and Archer TK (2003). Chromatin remodeling by nuclear receptors. Chromosoma 111: 495-504.

Islam KK (2009). Association Analyses of SNPs in Candidate Genes With Body fat Deposition and Carcass Merit Traits in Beef Cattle. Masters thesis, Department of Agricultural, Food and Nutritional Science, University of Alberta, Alberta.

Islam KK, Vinsky M, Crews RE, Okine E, et al. (2009). Association analyses of a SNP in the promoter of IGF1 with fat deposition and carcass merit traits in hybrid, Angus and Charolais beef cattle. Anim. Genet. 40: 766-769.

Jiang H and Lucy MC (2001). Variants of the 5'-untranslated region of the bovine growth hormone receptor mRNA: isolation, expression and effects on translational efficiency. Gene 265: 45-53.

Lagziel A and Soller M (1999). DNA sequence of SSCP haplotypes at the bovine growth hormone (bGH) gene. Anim. Genet. 30: 362-365.

Lechner MS, Levitan I and Dressler GR (2000). PTIP, a novel BRCT domain-containing protein interacts with Pax2 and is associated with active chromatin. Nucleic Acids Res. 28: 2741-2751.

Lucy MC (2008). Functional differences in the growth hormone and insulin-like growth factor axis in cattle and pigs: implications for post-partum nutrition and reproduction. Reprod. Domest. Anim. 43 (Suppl 2): 31-39.

Lucy MC, Hauser SD, Eppard PJ, Krivi GG, et al. (1993). Variants of somatotropin in cattle: gene frequencies in major dairy breeds and associated milk production. Domest. Anim. Endocrinol. 10: 325-333.

Manolio TA, Collins FS, Cox NJ, Goldstein DB, et al. (2009). Finding the missing heritability of complex diseases. Nature 461: 747-753.

Montgomery GW and Sise JA (1990). Extraction of DNA from sheep white blood cells. J. Agr. Res. 33: 437-441.

Moyes TE (2004). Variation in Concentrations of Insulin-Like Growth Factor-1 (IGF-1) in Pasture-Fed Holstein-Friesian Cows. Ph.D. thesis, University of Melbourne, Melbourne.

Mullen MP, Berry DP, Howard DJ, Diskin MG, et al. (2010). Associations between novel single nucleotide polymorphisms in the Bos taurus growth hormone gene and performance traits in Holstein-Friesian dairy cattle. J. Dairy Sci. 93: 5959-5969.

Mullen MP, Berry DP, Howard DJ, Diskin MG, et al. (2011). Single nucleotide polymorphisms in the insulin-like growth factor 1 (IGF-1) gene are associated with performance in Holstein-Friesian dairy cattle. Front. Genet. 2: 3.

Olori VE and Galesloot PJB (1999). Projection of partial lactations and calculation of 305-day yields in the republic of Ireland. Interbull Bull. 22: 149-154.

Patton J, Kenny DA, McNamara S, Mee JF, et al. (2007). Relationships among milk production, energy balance, plasma analytes, and reproduction in Holstein-Friesian cows. J. Dairy Sci. 90: 649-658.

Rajkumar K, Modric T and Murphy LJ (1999). Impaired adipogenesis in insulin-like growth factor binding protein-1 transgenic mice. J. Endocrinol. 162: 457-465.

Renaville R, Hammadi M and Portetelle D (2002). Role of the somatotropic axis in the mammalian metabolism. Domest. Anim. Endocrinol. 23: 351-360.

Rose MT, Weekes TE and Rowlinson P (2005). Correlation of blood and milk components with the milk yield response to bovine somatotropin in dairy cows. Domest. Anim. Endocrinol. 28: 296-307. 
Tatarakis A, Margaritis T, Martinez-Jimenez CP, Kouskouti A, et al. (2008). Dominant and redundant functions of TFIID involved in the regulation of hepatic genes. Mol. Cell 31: 531-543.

Siadkowska E, Zwierzchowski L, Oprzadek J, Strzalkowska N, et al. (2006). Effect of polymorphism in IGF-1 gene on production traits in Polish Holstein-Friesian cattle. Anim. Sci. Pap. Rep. Inst. Genet. Anim. Breed. 24: 225-237.

Umayahara Y, Kawamori R, Watada H, Imano E, et al. (1994). Estrogen regulation of the insulin-like growth factor I gene transcription involves an AP-1 enhancer. J. Biol. Chem. 269: 16433-16442.

Vorobyov E and Horst J (2006). Getting the proto-Pax by the tail. J. Mol. Evol. 63: 153-164.

Waters SM, McCabe MS, Howard DJ, Giblin L, et al. (2011). Associations between newly discovered polymorphisms in the Bos taurus growth hormone receptor gene and performance traits in Holstein-Friesian dairy cattle. Anim. Genet. 42: 39-49.

Wildman EE, Jones GM, Wagner PE, Boman RL, et al. (1982). A dairy cow body condition scoring system and Its relationship to selected production characteristics. J. Dairy Sci. 65: 495-501.

Yao J, Aggrey SE, Zadworny D, Hayes JF, et al. (1996). Sequence variations in the bovine growth hormone gene characterized by single-strand conformation polymorphism (SSCP) analysis and their association with milk production traits in Holsteins. Genetics 144: 1809-1816.

Zhang Y, Du H, Chen J, Yang G, et al. (2008). Porcine growth differentiation factor 9 gene polymorphisms and their associations with litter size. J. Genet. Genom. 35: 163-169. 